\title{
Ultrasonographic findings in hyperimmunoglobulin D syndrome: a case report
}

\author{
Laura Damian ${ }^{*}$, Otilia Fufezan²*, Mihaela Farcău², Simona Tătar², Călin Lazăr³, \\ Dorin Farcău ${ }^{3}$
}

${ }^{1}$ Emergency Clinical County Hospital, Rheumatology Department, ${ }^{2}$ Children Emergency Clinical County Hospital, $3^{\text {rd }}$ Pediatric Department, ${ }^{3}$,Iuliu Haţieganu” University of Medicine and Pharmacy, 2nd Pediatric Department, ${ }^{4}$,Iuliu Haţieganu" University of Medicine and Pharmacy, $3^{\text {rd }}$ Pediatric Department, Cluj-Napoca, Romania

*the authors share the first authorship

\begin{abstract}
Hyperimmunoglobulin D syndrome due to mevalonate kinase deficiency is a rare autoinflammatory disease with digestive tract involvement. We report an 11-year female child who has presented since the age of 1 year, bouts of fever, rash, joint swelling, pulmonary consolidation, lymph node involvement and hepatosplenomegaly. Hyperimmunglobulin D and increased urinary mevalonic acid were detected. The ultrasonographic features of hepatosplenomegaly ranged from increment in size to pseudotumoral involvement, with hypoechogenic masses without apparent wall. Abdominal CT during a disease flare showed hypodense, hypoenhancing nodular lesions, suggesting metastases. Nevertheless, a thorough search for malignancy was negative and the masses disappeared after the flare. Mevalonate kinase deficiency may add to the causes of hepatosplenic and pulmonary inflammatory pseudotumors.

Keywords: hyperimmunoglobulinemia D; mevalonate kinase deficiency; inflammatory pseudotumor; pulmonary ultrasonography.
\end{abstract}

\section{Introduction}

Mevalonate kinase deficiency (MVK) is an autosomal recessive autoinflammatory metabolic syndrome, due to mutations of the $M V K$ gene on the $12 \mathrm{q} 24.3$ chromosome, encoding mevalonate kinase. Depending on the amount of functional enzyme, MVK expression ranges from hyperimmunglobulinemia D (HIDS), characterized by periodic fever with rash, adenomegaly, abdominal pain, and diarrhea, to mevalonic aciduria, with dysmorphism, hepatopathy, and neurologic dysfunction $[1,2]$.

Received 29.11.2016 Accepted 07.02.2017

Med Ultrason

2017, Vol. 19, No 2, 224-227

Corresponding author: Laura Damian

Emergency Clinical County Hospital Cluj,

Rheumatology Department,

2-4 Clinicilor Street, 400006 Cluj-Napoca,

Fax: 0264431040

E-mail: lauradamiancj@yahoo.com
We present the ultrasonographic findings in a pediatric case with recurrent fever, hepatomegaly and/or splenomegaly, and pulmonary consolidation, finally proven to have HIDS/MVK.

\section{Case report}

An 11-year girl, first child of unrelated healthy parents, with no dysmorphic features and normal neurologic development, was repeatedly seen since the age of 11 months for episodes of fever lasting for 4-6 days, pharingeal erythema, aphtae, cervical lymph nodes enlargement, pneumonia, abdominal pain, diarrhea and rash. Laboratory revealed during these flares, acute phase reactants (erythrocyte sedimentation rate [ESR] up to 140 $\mathrm{mm} / \mathrm{h}$, C-reactive protein $36 \mathrm{mg} / \mathrm{dl}$ ), leukocytosis with neutrophilia, increased ferritin, normal liver enzymes, and no cholestasis markers. ESR remained elevated between the attacks (ESR around $40 \mathrm{~mm} / \mathrm{h}$ ). IgD values were found repeatedly high (up to $1570 \mathrm{IU} / \mathrm{mL}$, normal 
range $<100 \mathrm{IU} / \mathrm{mL}$ ), parallel with high IgA values. Urinary mevalonic acid was $10.9 \mathrm{mmol} / \mathrm{creatinin} \mathrm{mol}$ (normal range $<1.3 \mathrm{mmol} / \mathrm{creatinin} \mathrm{mol}$ ). The genetic tests were not available.

During follow-up the hepatosplenic and lymph node involvement raised important differential diagnosis problems. A liver biopsy at the age of 18 months had revealed very large hepatocytes with folded cytoplasm and PAS-positive intracitoplasmatic granules, sinusoid capillarisation and some fibrotic deposition in the portal spaces. Abdominal ultrasonographic follow-up was performed using a Toshiba Xario V 2.0 ultrasound machine with 8-14 MHz liniar probe and 3-6 MHz convex probes. Splenomegaly and/or hepatomegaly were almost constant findings during the flares, sometimes with reversible hyperechoic images without acoustic shadowing. Ultrasonography also detected other sites of inflammation (articular, sinusal, or pleuropulmonary). Enlarged lymph nodes were found during attacks, rarely with hyperechoic center evoking inflammation and necrosis, or pseudotumoral appearance (Table I).
During a severe acute inflammatory episode, at the age of 11, several hypoechoic pseudotumoral hepatosplenic masses without apparent wall were detected (fig 1-2). The thoraco-abdominal CT (T1-weighted) revealed similar hypodense, hypoenhancing nodular lesions, suggestive of metastases, disseminated in the liver and spleen. However, all the lesions in the liver and spleen completely disappeared spontaneously within 2 months, and were therefore considered to be pseudotumors.

During the same described flare, lung ultrasonography found fluid in the left pleural space and areas of consolidation (fig 3). Extensive screening for infection was nevertheless negative and empiric antibiotic therapy unsuccessful. The lesions were completely reversible after corticosteroids.

After the diagnosis of HIDS/MVK, therapy consisted of corticosteroids during flares. Other medications such as anti-IL-1 (anakinra, canakinumab) and anti-TNF were not employed due to the current lack of national reimbursement for this diagnosis.

Table I. Ultrasonographic hepatosplenic and lymph node findings during longitudinal follow-up.

\begin{tabular}{|c|c|c|c|c|}
\hline \multicolumn{2}{|l|}{ Age } & Liver & Spleen & Lymph nodes \\
\hline \multicolumn{2}{|c|}{$11 \mathrm{mo}$} & normal & normal & \\
\hline \multicolumn{2}{|l|}{$1 \mathrm{y}$} & normal & $\begin{array}{l}100 \mathrm{~mm} \text {, hyperechoic dots, } \\
\text { without shadow }\end{array}$ & \\
\hline \multicolumn{2}{|c|}{$18 \mathrm{mo}$} & LNB, RL $100 \mathrm{~cm}$ & $80 \mathrm{~mm}$ & \\
\hline \multicolumn{2}{|l|}{$3 y$} & $\begin{array}{l}\text { Hepatosplenomegaly, normal echo- } \\
\text { structure, RL } 100 \mathrm{~mm} \text {, LL 74/43 mm, } \\
\text { CL } 18 \mathrm{~mm}\end{array}$ & $105 \mathrm{~mm}$ & \\
\hline \multicolumn{2}{|l|}{$5 \mathrm{y}$} & $\begin{array}{l}\mathrm{RL} 120 / 107 \mathrm{~mm}, \mathrm{LL} 45 \mathrm{~mm}, \mathrm{CL} 23 \\
\mathrm{~mm}(>)\end{array}$ & Splenomegaly (115 mm) & $\begin{array}{l}\text { Hepatic hilum, mesenteric and right } \\
\text { iliac }(<15 \mathrm{~mm})\end{array}$ \\
\hline \multicolumn{2}{|l|}{$6 \mathrm{y}$} & RL 130 mm, CL normal & $120 \mathrm{~mm}$ & $\begin{array}{l}\text { Cervical, submandibular, mesenteric, } \\
\text { iliac }(<15 \mathrm{~mm})\end{array}$ \\
\hline \multicolumn{2}{|l|}{$7 \mathrm{y}$} & RL 115 mm, LL 42 mm, CL $22 \mathrm{~mm}$ & $100 \mathrm{~mm}$ & $\begin{array}{l}\text { Mesenteric, right iliac fossa }(14 / 7 \\
\mathrm{mm}) \text {, right jugular block }(25 \mathrm{~mm})\end{array}$ \\
\hline \multicolumn{2}{|l|}{$8 \mathrm{y}$} & Normal & Normal & $\begin{array}{l}\text { Hepatic hilum }(14 \mathrm{~mm}) \text { mesenteric } \\
(11 \mathrm{~mm})\end{array}$ \\
\hline \multicolumn{2}{|l|}{$10 \mathrm{y}$} & $\begin{array}{l}\text { RL } 140 \mathrm{~mm} \text { in renal axis, LL } 43 \mathrm{~mm} \text {, } \\
\text { CL } 28 \mathrm{~mm}\end{array}$ & $115 \mathrm{~mm}$ & $\begin{array}{l}\text { Cervical (several vascular poles, } \\
\text { increased stiffness) }\end{array}$ \\
\hline \multirow[t]{5}{*}{$11 \mathrm{y}$} & onset & $\begin{array}{l}\text { RL } 148 \mathrm{~mm} \text {, inferior rounded mar- } \\
\text { gin; focal inhomogenous hypoechoic } \\
\text { areas without apparent wall, } 6-7 \mathrm{~mm} \\
\text { diameter, with no vascularisation, } \\
\text { suggesting granulomas or metastases }\end{array}$ & $\begin{array}{l}\text { Splenomegaly } 130-150 \mathrm{~mm} \text {, } \\
\text { with similar inhomogenous } \\
\text { hypoechoic areas without ap- } \\
\text { parent wall, } 6-7 \mathrm{~mm} \text { diameter, } \\
\text { with no vascularisation }\end{array}$ & $\begin{array}{l}\text { Intrapleural lymph nodes (right } 12 / 7 \\
\text { mm, left } 8 / 4 \mathrm{~mm}) \\
\text { Hepatic hilum }(9 / 12 \mathrm{~mm} \text { - up to } \\
15 \mathrm{~mm}\end{array}$ \\
\hline & after 2 wks* & $\begin{array}{l}\text { RL } 155 \mathrm{~mm} \text {, rounded margin; a } \\
\text { single hypoechoic lesion }\end{array}$ & $\begin{array}{l}123 \mathrm{~mm} \text {, without focal hypo- } \\
\text { echoic areas }\end{array}$ & $\begin{array}{l}\text { Mesenteric lymph nodes, up to } 11 \mathrm{~mm} \text {, } \\
\text { no hepatic hilum adenomegaly }\end{array}$ \\
\hline & after 5 wks* & $\begin{array}{l}\text { RL } 145 \mathrm{~mm} \text {, normal margin, without } \\
\text { focal lesions }\end{array}$ & $\begin{array}{l}127-138 \mathrm{~mm} \text {, a single } 4 \mathrm{~mm} \\
\text { hypoechoic area }\end{array}$ & $\begin{array}{l}\text { Mesenteric lymph nodes up to } \\
13 \mathrm{~mm}\end{array}$ \\
\hline & after 7 wks* & RL $140 \mathrm{~mm}$, normal structure & $110 \mathrm{~mm}$, normal structure & No \\
\hline & after $4 \mathrm{mo}^{*}$ & RL $143 \mathrm{~mm}$ & $118 \mathrm{~mm}$ & No \\
\hline
\end{tabular}

LL - left lobe, RL -right lobe, CL - caudate lobe, LNB - liver needle biopsy, *from flare onset, y - years, mo - months, wks - weeks 


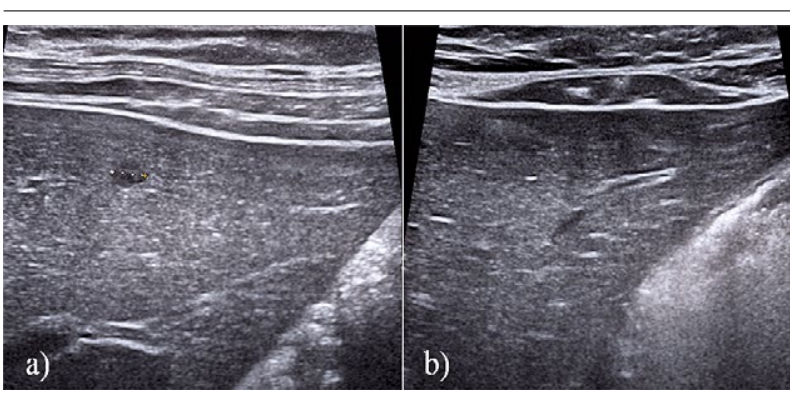

Fig 1. Liver US examination at the age of 11: a) Transverse section on the left liver lobe revealed a small hypoechoic lesion, without apparent wall; b) Control after 4 months did not detect focal liver lesions.

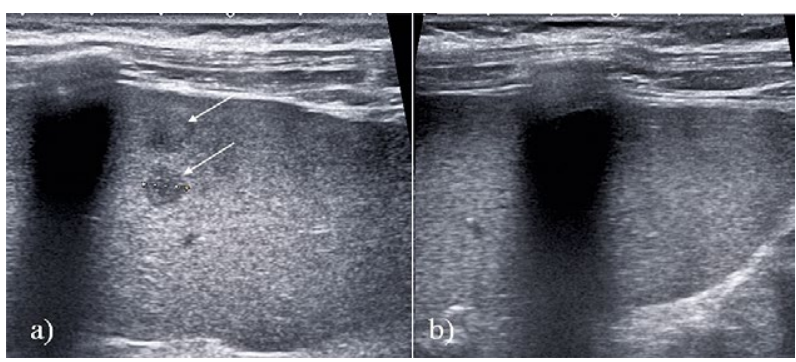

Fig 2. Spleen US at the age of 11, coronal section on the left flank: a) There are two lesions with the same US pattern as the liver lesion described in fig. 1 (arrows); b) 4 months later the spleen parenchyma had a homogenous structure.

\section{Discussions}

MVK affects at least 300 people worldwide, most of them with HIDS [2]. Many cases start before one year of age, but later onset is also reported [2,3]. HIDS flares are triggered by vaccination, infections, minor trauma,

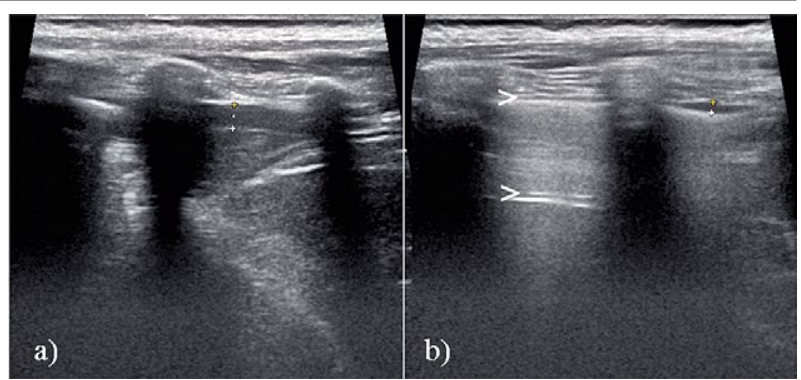

Fig 3. Pleuropulmonary US aspects at the age of 11: a) Longitudinal section of the left posterior hemithorax, subscapular area showed fluid and absence of the "A lines" (between calipers) b) Longitudinal US scan of the left posterior hemithorax (examination was done after 3 weeks) detected normal "A lines" (white arrowheads), representing normal lung parenchyma and very thin pleural effusion (between calipers).

stress, etc. The diagnosis is sustained by high $\operatorname{IgD}$ and IgA and elevated urinary mevalonic acid, and confirmed genetically whenever possible [1,2].

Gastrointestinal inflammation is frequent in MVK $[3,4]$. Generally, hepatosplenomegaly is detected in mevalonic aciduria, along with dysmorphic features and severe neurologic impairment, absent in our case [5]. Liver involvement in MVK may manifest as neonatal hepatitis, hepatomegaly or hepatosplenomegaly, cholestatic liver dysfunction, hepatic fibrosis, or even hepatic failure [6-8]. MVK mimicks metabolic, infectious, chromosomial, hematologic, or neoplastic diseases $[1,3]$. Liver biopsy reveals an inflammatory lymphocytic infiltrate, such as in our case, associated with portal fibrosis [7] or histiocyte infiltration with hemophagocytosis [8].

There are few data regarding ultrasonography in pediatric patients with HIDS/MVK, although it may be

Table II. Potential uses of ultrasonography in children with mevalonate kinase deficiency

\begin{tabular}{ll}
\hline Procedure & Possible findings in MVK \\
\hline Abdominal US & Hepatosplenomegaly (with normal or inhomogenous structure) \\
& Hepatic fibrosis \\
& Pseudotumoral masses (focal inhomogenous hypoechoic areas without apparent wall and no vascu- \\
& larisation) \\
& Renal angiomyolipoma \\
& Abdominal lymph nodes enlargement \\
& Peritonitis, ascites, pelviperitonitis \\
US-guided biopsy & Inflammation, fibrosis \\
Cervical lymph node US & Lymph nodes enlargement (unilateral or bilateral) \\
& Pseudotumoral aspects (increased vascularisation and stiffness, multiple vascular poles) \\
Colonic hydrosonography & Increased wall thickness of the terminal ileon and colon \\
& Altered stratification \\
Pulmonary US & Pleuritis/pleuresia \\
& Pulmonary consolidation \\
Maxillary US & Pleural and/or pulmonary pseudotumoral irregular hyperechic masses (pseudotumors) \\
Articular US & Sinusitis \\
& Synovitis (knee, tibio-tarsal) \\
& Erosions (rarely) \\
\hline
\end{tabular}


a valuable tool (table II) as heterogenous hepatosplenomegaly may be seen [7]. In our patient, the hypoechoic hepatosplenic masses with rapid regression were likely inflammatory pseudotumors, mass-forming lesions characterized by a prominent inflammatory infiltrate. Liver pseudotumors are hypoechoic or hyperechoic masses, with hypoattenuating parenchyma on unenhanced $\mathrm{CT}$, and hypointense lesions on T1-weighted and hyperintense on T2-weighted images after contrast administration [9].

Another peculiarity in our case was the recurrent pulmonary consolidation, uncommon in HIDS. The differentiation from infection was difficult, inasmuch as the defense against Pneumococcus is impaired in HIDS/MVK, and the attacks are usually triggered by infections, sometimes occult $[3,6]$. Nevertheless, the negative exhaustive search for infections and the remission after corticosteroids pointed to lung inflammatory pseudotumors [10].

In conclusion liver and splenic involvement in MVK may be misleading. Ultrasonography is an important tool for follow-up, mainly in children. The diagnosis of HIDS/MVK could be included in the differential list of hepatosplenomegaly, adenomegaly, and recurrent pulmonary consolidation, as well as in the lymphoma mimickry. Also, HIDS/MVK may be another cause of inflammatory pseudotumors, with spontaneous resolution.

\section{References}

1. De Pieri C, Taddio A, Insalaco A, et al. Different presentations of mevalonate kinase deficiency: a case series. Clin Exp Rheumatol 2015;33:437-442.
2. Favier LA, Schulert GS. Mevalonate kinase deficiency: current perspectives. Appl Clin Genet 2016;9:101-110.

3. Durel CA, Aouba A, Bienvenu B, et al. Observational study of a French and Belgian cohort of 23 patients diagnosed in adulthood with mevalonate kinase deficiency. Medicine 2016;95:e3027.

4. Oretti C, Barbi E, Marchetti F, et al. Diagnostic challenge of hyper-IgD syndrome in four children with inflammatory gastrointestinal complaints. Scand J Gastroenterol 2006;41:430-436

5. Haas D, Hoffmann GF. Mevalonate kinase deficiency: from mevalonic aciduria to hyperimmunoglobulinemia D syndrome. Orphanet J Rare Dis 2006;1:13.

6. Drenth JP, Haagsma CJ, van der Meer JW. Hyperimmunoglobulinemia D and periodic fever syndrome. The clinical spectrum in a series of 50 patients. International HyperIgD study group. Medicine 1994;73:133-144.

7. Harel-Meir H, Bujanover Y, Berkun Y, Goldstein N, Anikster Y. Mevalonic aciduria in a child featuring hepatic fibrosis and novel mevalonate kinase mutations. The Open Pediatric Med J 2009; 3:45-47.

8. Schulert GS, Bove K, McMasters R, Campbell K, Leslie N, Grom AA. 11-Month-old infant with periodic fevers, recurrent liver dysfunction, and perforin gene polymorphism. Arthritis Care Res (Hoboken) 2015;67:11731179 .

9. Balabaud C, Bioulac-Sage P, Goodman ZD, Makhlouf HR. Inflammatory pseudotumor of the liver: a rare but distinct tumor-like lesion. Gastroenterol Hepatol (NY) 2012;8:633634.

10. Lindemans CA, Bruinsma RA, Nikkels PG, Broker FH, Arets HG. Pulmonary consolidation and inflammation: inflammatory pseudotumour in young children. Monaldi Arch Chest Dis 2009;71:71-75. 